\title{
LOS DOCTRINEROS Y LA EXTIRPACION \\ DE LA RELIGION INDIGENA EN EL ARZOBISPADO DE LIMA, 1600-1620
}

\author{
Por Antonio Acosta Rodríguez
}

I. Revisión de los planteamientos sobre el tema

El estudio de las religiones indígenas y de los problemas relacionados con ellas en lo que fue el área de influencia incaica se aborda hoy desde diversas perspectivas relacionadas entre sí. Una de estas es la del análisis de la religión en si misma ${ }^{1}$. Los trabajos que se realizan con este objetivo tienen como marco cronológico un período amplísimo que va desde mucho antes de la conquista española hasta nuestros días, utilizando fuentes como la arqueología, la mitología, los trabajos de campo actuales, etc. .. .

Un matiz diferente incorporan los estudios que consideran la aculturación sufrida por las religiones indígenas, tanto en el período prehispánico como en el colonial español y en el nacional. La conquista incaica, por ejemplo, modificó las religiones regionales anteriores y no hace falta decir que la implantación del catolicismo hizo lo propio con la situación religiosa existente en los Andes a comienzos del siglo $\mathrm{XVI}^{3}$.

1) Me refiero a los problemas derivados de las condiciones materiales y sociales en que vive el hombre y que influyen en el conjunto de las relaciones que establece con lo que considera superior a sí mismo, con lo sobrenatural. Cfr. M. Mes lin, Aproximación a una ciencia de las religiones. Madrid 1978, p. 13.

2) La bibliografía que se podría citar sería abundantísima y variada. Unicamente a título de ejemplo citaré: J. M u $\mathbf{r}$ a, «La función del tejido en varios contextos sociales y políticos", en: Formaciones económicas y políticas del mundo andino. Lima 1975, pp. 145-170 (el trabajo data de 1958); R. T. Z u i d e m a, "Mito e historia en el antiguo Perú", en: Allpanchis, no 10, Cuzco 1977, pp. 15-52; en general, los números 3 (1971) y 9 (1976) de la misma revista; M. M a r 2 a l, Estudios sobre religión campesina, Lima 1977.

3) Sólo a manera de indicación citaré: Ideología mesiánica del mundo 
En el marco más reducido de la historia de la colonización española, de manera estrechamente unida al enfoque anterior, se encuentra el estudio de los problemas relacionados con las prácticas religiosas indígenas durante dicho período. Bajo el prisma específico del fenómeno colonial, parece obvio que el estudio de la evolución de las estructuras mentales y religiosas indigenas ha de abordarse en un contexto amplio, que englobe fenómenos que tienen lugar simultáneamente en los planos social y económico. Sobre esta base, el presente trabajo está dedicado a algunos hechos que ayudan a comprender el tratamiento que mereció por parte española la práctica religiosa indígena $y$, concretamente, la actitud que se adoptó, a comienzos del siglo XVII, en lo que fue llamado por el propio sector colonizador las campañas de extirpación de la idolatría. Con respecto a dicha actitud, $\mathrm{mi}$ intención se centra en estudiar su aparición y sus causas ${ }^{4}$.

En relación con el comienzo de estas campañas en 1609 en Lima, a raiz de la denuncia efectuada por el doctrinero de San Damián de Huarochirí, Francisco de Avila, hay dos cuestiones claves que, en cierto modo, han sido ya planteadas con anterioridad, aunque no contestadas: 1) ¿Qué cambió hacia 1600 en el panorama colonial para que la Iglesia se decidiera a sistematizar, extender e intensificar lo que hasta entonces había sido sólo una más de sus preocupaciones - aunque muy importante -: la extirpación de la religión indígena, institucionalizándola al crear la figura de "Juez Visitador de Idolatrías»? 2) ¿Por qué el movimiento antiidolátrico surgió en el arzobispado de Lima y no fue seguido con la misma intensidad, o con ninguna, en otros lugares? ${ }^{5}$.

andino (recop. Juan M. Os s i o), Lima 1973; F. P e a s e, El dios creador andino, Lima 1973; L. M i 1 I o n e s, Introducción al proceso de aculturación religiosa indígena. Lima 1967.

4) Las referencias a este momento son frecuentes en la historiografía sobre el Perú colonial. Específicamente ha sido objeto de estudio, por ejemplo, por L. Millon es, op. cit. y por P. D u vi ols, La lutte contre les religions autochtones dans le Pérou colonial. "L'extirpation de l'idolâtrie»" entre 1532 et 1660. Lima, s/f. (1971). En adelante tomaré este trabajo como asiduo punto de referencia.

5) P. Du vi ols, op. cit. p. 174 y del mismo autor, «La represión del paganismo andino y la expulsión de los moriscos», en: Anuario de Estudios Americanos, vol. XXVIII, Sevilla 1971, pp. 201-207. 
Hasta el momento no se ha avanzado mucho para responder satisfactoriamente a estas preguntas. $\mathrm{Mi}$ intención es contribuir a la respuesta de la primera de ellas, al menos: por qué la extirpación apareció con una intensidad inusitada en la fecha y zona citadas. En cuanto a por qué no surgió con las mismas características en otros lugares aparentemente similares, puede ser tarea para otro trabajo. Hay que reconocer, de todas formas, que aún falta bastante por investigar sobre la realidad colonial antes de que sepamos cuanto haría falta para poder contestarlo.

Como ya he apuntado, la primera de las cuestiones ha sido ya formulada, pero partiendo de un planteamiento defectuoso, en mi opinión, que ha hecho que su respuesta no se haya encontrado con facilidad. Dicho planteamiento ha consistido exactamente en preguntarse por los cambios ocurridos en el seno de la Iglesia, con mayúsculas, se podría añadir, pensando en las capas altas de ila jerarquía eclesiástica limeña, para que decidiera poner en maŕcha un gran despliegue de recursos cuando prestó atención a la denuncia de Avila en 1609. Enfocar la cuestión de este modo significa adoptar una óptica exterior a la aparición misma del fenómeno, que sólo entra en juego después de la denuncia de Avila. $\mathrm{Y}$ aunque en ciertos aspectos considerar la cuestión así puede resultar útil, en ningún momento permite preguntarse por los motivos que movieron a Avila a hacer la denuncia de las prácticas religiosas indígenas ante el arzobispado de Lima, ni por las razones de la fuerza que mantuvo a dicha denuncia, una vez dado el primer paso ${ }^{6}$.

En un trabajo anterior a éste, refiriéndome a la misma cuestión, apunté la conveniencia de hacer un replanteamiento del estado de la cuestión, trasladando el centro de atención de las explicaciones dadas tradicionalmente al tema a otras posibles causas que hasta el momento no han sido suficientemente valoradas ${ }^{7}$. Se pueden distinguir diferentes posturas en la historiografia existente a la hora de explicar la aparición institucionalizada de la

6) P. D u vio I s, La lutte. ...p. 174.

7) A. A c o s t a, "El pleito de Ios indios de San Damián (Huarochirí) contra Francisco de Avila. 1607\%, en: Historiografía y Bibliografía Americanistas, vol. XXIII, Sevilla 1979, pp. 3-33. 
persecución de la religión indígena. Quizás la primera que quepa diferenciar es la que ha optado por afirmar que ello se debió a que, a comienzos del siglo XVII, se produjo un "rebrote" de las prácticas indígenas, ante el cual la Iglesia reaccionó intensificando su labor mediante las campañas extirpadoras ${ }^{8}$. Pero, hasta el momento, no se conoce documentación que apoye la idea de que las prácticas religiosas indígenas rebrotaron a comienzos del siglo, lo que conduce a la conclusion de que la tesis del rebrote es más intuitiva que fundada. Podría haberse esgrimido antes, con el surgimiento del Taki Onkoy, por ejemplo, pero no se hizo. Por el contrario, en la época que estudiamos no hubo ningún movimiento mesiánico de la importancia de aquél $\mathrm{y}$, según todos los indicios, las prácticas religiosas indígenas se mantuvieron sin grandes altibajos hasta $1609^{9}$.

Frente a esta pretendida explicación que parte del terreno de la propia religión indígena exclusivamente, por otro lado se ha llegado a presentar toda una serie de «circunstancias» localizadas en el exterior del mundo indígena para intentar explicar, no tanto la denuncia de F. de Avila, cuanto el eco que tuvo en los jerarcas limeños ${ }^{10}$. La primera de ellas procede del propio $F$. de Avila y se basa en la idea de que la idolatría se "descubrió" en 1608. A pesar de haber sido adoptada por algunos historiadores, tal explicación parece insostenible, dada la enorme tradición de combate a la religión indígena que llegó hasta los mismos momentos anteriores al pretendido descubrimiento. Por haber sido

8) A. E g a ñ a, SJ., Historia de la Iglesia en la América Española. Hemis ferio Sur. Madrid 1956, p. 282; F. de A r m a s, «La pervivencia de las idolatrías y las viritas para extirparlas, en: Boletín del Institu to Riva-Aguiero, vol. 7, Lima 1966-8, pp. 7-28 (v. especialmente pp. 20 y s8.); P. C a s t a ned a, "Don Bartolomé Lobo Guerrero, tercer Arzobispo de Lima", en: Anuario de Estudios Americanos, vol. XXXIII, Sevilla 1976, pp. 57-103 (v. esp. p. 74).

9) Así pensaba también B. Lobo Guerrero: cfr. su carta al Rey de 20 Abril 1611 reproducida en: Dioses y hombres de Huarochirí. Narración quechua recogida por Francisco de Avila (1598?), ed. J. M. A r g u e d a s, con estudio bio-bibliográfico de P. D u vi o ls. Lima 1966, p. 259. V. también P. Du vi o 1 s, La lutte. .., p. 147 y nota 93 de p. 174. - Después del Taki Ongoy continuaron, ocasionalmente, otros intentos similares aunque de menor fuerza, como los de Antabamba (1591) o Moro Onqoy (1616).

10) P. D u viols, ibíd., p. 174 y ss. 
ampliamente rebatida en otro lugar, me ahorraré dedicarle más atención ${ }^{11}$.

Otra de estas "circunstancias» tiene un carácter más coyuntural y se refiere a la coincidencia del comienzo de las campañas de extirpación y la expulsión de los moriscos de la Península, en 1609. Tras mantenerse que ambos hechos "fueron decididos en un mismo espíritu de purificación religiosa", lo que ya sería discutible de por si $^{12}$, se pasó a afirmar la necesidad de establecer una relación de causa-efecto entre ambos, lo que, definitivamente, no parece que se pueda defender ${ }^{13}$. No existen, en absoluto, pruebas para demostrarlo y las aducidas, desde luego, no tienen validez. No lo demuestra que Arriaga relacionara en 1620, "a posteriori", ambos fenómenos, haciéndolo precisamente para diferenciarlos. Lógicamente la comparación resultaba casi obligada algunos años después pero, como el mismo Arriaga señalaba, había diferencias entre los moriscos y los indios; lo único que los unía era que se trataba de comunidades con raíces religiosas ajenas al catolicismo ${ }^{14}$.

Igualmente, siguiendo en la misma línea, no disponemos ni siquiera de un texto, previo a las campañas de extirpación y génerado en círculos próximos al fenómeno, que haga pensar que existía en el virreinato peruano el temor de que la proximidad de los holandeses en el Pacíficio Sur podía poner en peligro la integración religiosa de la población indígena del arzobispado de Lima. El hecho de que F. de Avila, en 1645, utilizara el argumento en uno de sus sermones a los indios no demuestra, en lo más mínimo, que ello fuera la causa que, en 1610 , decidió el comienzo de la persecución de la idolatría, y otros textos que se han manejado no añaden nada para probarlo ${ }^{15}$.

11) En general mantienen esta tesis los mismos autores que hablan de «rebrote». V. nota 8. La tesis ha sido refutada por P. D u v i o ls en ibíd.

12) P. D u vi o ls, La lutte. ., p. 177.

13) P. Duvi o l s, «La represión. ..., p. 177.

14) P. Pablo Joseph de A r r i a 8 a, SJ., Extirpación de la Idolatría del Pirú. Lima 1621, pp. 1-2. Contraponiéndolo al caso de los moriscos, decía A r r i a g a «. . . No está encancerado el mal de nuestros indios》.

15 ) Cfr. P. D u vi ols, Lalutte..., p.178y ss. Aparte de lo débil que resulta el argumento del sermón de Avila, no parece más consistente la 
Evidentemente, no hay que descartar la posibilidad de que todas estas circunstancias pudieran haber influido en algunas personas y fuesen factores que ayudaran a animar las campañas, pero esta posibilidad sólo habría tenido validez una vez que aquéllas hubieron comenzado y no antes.

Por otra parte, parece imposible negar la importancia de la Compañía de Jesús en el desarrollo de la extirpación a partir de 1610 , desde que Avila le pidió ayuda antes de realizar la denuncia oficial en Lima. Los jesuitas ya se habían preocupado, desde su misma llegada al virreinato, por la religión indígena, trabajando precisamente en Huarochirí en 1570. A comienzos del siglo XVII continuaban realizando misiones temporales en zonas de las mismas doctrinas de las que surgieron los curas que se dedicaron a la extirpación. Además, estaban reconocidos como buenos confesores y predicadores, precisamente algo de lo que hacía falta para combatir intensamente las prácticas indias. Por estas razones y porque había estudiado con ellos, no es extraño que Avila acudiera en su ayuda en 1609 . Enfin, no cabe duda de que los jesuitas cumplieron un papel importante en el desarrollo de las campañas pero, una vez más, no se puede afirmar que ex ante influyeran en la decisión de Avila de efectuar la denuncia ${ }^{16}$.

Frente a la insuficiencia de estas razones para explicar el origen del asunto, existe un factor que sí ayuda a entender la actitud adoptada en Lima tras la llegada de F. de Avila en 1609. A fines del siglo XVI y comienzos del XVII se estaban produciendo con cierta frecuencia nombramientos de obispos y arzobispos en sedes americanas de individuos anteriormente relacionados con la

referencia a la obra de $F$, de $Q$ u e v e d o, «La Fortuna con seso y la Hora de todos», en: Obras completas, Tomo I. Ed. Aguilar, Madrid 1969, pp. 226-280. Escrita en 1635, en cierto pasaje fantástico, sin relación con el problema que nos ocupa, $Q u$ eved o hace coincidir el componente morisco, holandés e indio de Chile. La frase dedicada a éste último «. . . que guarda belicosamente su libertad para su condenación en su idolatría.... ibid. p. 260 parece haber dado pié a $\mathrm{D}$ u vi o l s para defender su argumento. - Tampoco se puede decir que una prueba de peso sea la obra de Fr. José A $\mathrm{m}$ i ch, Compendio histórico de los trabajos, fatigas, sudores, y muertes que los ministros evangélicos de la Seráfica Religión. . . París 1854, que hace alusión a un acontecimiento de mediados del siglo XVIII.

16) P. Duviols, La Lutte..., p. 181 y ss. 
Inquisición y uno de ellos fue Bartolomé Lobo Guerrero ${ }^{17}$. Esta tendencia podría ser tenida en cuenta en una discusión sobre la posible existencia del espíritu de purificación religiosa al que se aludió más arriba. Al margen de su experiencia en la Inquisición, Bartolomé Lobo aportó a las campañas que se iniciaron en 1610 una experiencia previa en el combate de la idolatría que hay que valorar en mayor medida que el resto de las circunstancias externas del movimiento.

De Inquisidor General en México, Lobo Guerrero fue promovido, en 1595, a arzobispo de Santa Fe y, una vez en su diócesis, uno de los padres jesuitas a los que llevó de ayudantes desde México constató la existencia de prácticas idolátricas indígenas en el Nuevo Reino de Granada. A raiz de ello, el propio arzobispo inició una visita de su distrito, hacia 1600 , destruyendo un gran número de ídolos y predicando, en compañía del mismo jesuita. No obstante, cuatro años más tarde el mismo Lobo comprobaba que aquella campaña no había sido de mucha utilidad y que los indios continuaban con sus prácticas religiosas ${ }^{18}$.

Lobo Guerrero estaba, pues, sensibilizado ante el tema de la religión indígena cuando llegó de arzobispo a Lima en 1608, además, tenía experiencia en su extirpación y sentía preferencia por los jesuitas, en general, pero también a la hora de hacer frente a este problema. Pues bien, con todo, aún hace falta un componente que marque la diferencia entre la experiencia colombiana de Lobo Guerrero y las otras muchas que hubo en el mismo territorio peruano anteriormente, de la que iba a iniciarse en 1610 en Lima. Componente que tiene que estar relacionado con la denuncia efectuada por Avila a la que Lobo presté su apoyo. La hipótesis que planteo es que este componente hay que encontrarlo en el plano de las relaciones entre los doctrineros de indios con sus comunidades en el arzobispado de Lima y en algunas circunstancias derivadas de las mismas. En dicho plano se combinaba el

17) Así, por ejemplo: Alonso Avalos Granero, obispo de Charcas en 1581; Antonio de la Raya, de Cuzco en 1594; Alonso Peralta, en Charcas en 1610; Agustín de Carvajal, en Huamanga en 1614 y F. Verdugo, en Huamanga en 1623. V. A.de E g a ñ a, op. cit., pp. 367, 309, 370, 339 y 340.

18 ) J. M. P a c h e c o, SJ., Los jesuitas en Colombia, I, (1567-1654). Bogotá 1959, pp. 75-77. 
ejercicio de la dominación colonial, en su manifestación tanto económica como ideológica, y los conflictos a que daba lugar adquirieron en Lima unas características particulares.

Ya en el terreno de los curas de indios, la figura de F. de Avila proporciona un primer aspecto interesante, aunque circunstancial, que rodea a su denuncia. Se trata de la vehemencia y gran dosis de teatralidad con que la llevó a cabo, que deja traslucir su profundo conocimiento de la religión indígena, difícil de adquirir en pocos meses y que, más bien, debía ser fruto de sus experiencia a lo largo de muchos años de cura en S. Damián ${ }^{19}$.

Pero, más importante que esto es la valoración de su propia figura, con lo que se comienza a entrar en el núcleo del asunto. Avila era sólo uno más de entre muchos doctrineros de indios que atravesaban por circunstancias parecidas en el arzobispado de Lima y por lo que, algunos de los cuales, se iban a mostrar dispuestos a secundarle en su iniciativa cuando se pusiera en marcha la primera campaña de extirpación, en 1610. Hasta hoy el cura de $\mathrm{S}$. Damián ha sido considerado en sí mismo, erróneamente, de una forma quizás excesivamente personalista. Aunque a Fernando de Avendaño, Alonso Osorio, Rodrigo Hernández Principe, etc., se les ha tenido en cuenta como visitadores de la idolatría, sin embargo, se ha pensado muy poco en ellos como curas de indios, antes del inicio de las campañas. De hecho Avila era uno más de los doctrineros que desde el siglo anterior se hallaban en conflicto manifiesto con distintos sectores de la sociedad colonial, aunque fundamentalmente con sus propias comunidades de indios, por motivos esencialmente económicos. En este clima de confrontación, llevada en abundantes casos al extremo de procesos judiciales con los curas, es donde la figura de F. de Avila cobra su completo y verdadero significado ${ }^{20}$.

19) V. la narración de P. J. A r r i a g a, op. cit., p. 3, y más tarde, del propio Francisco de Avila en su Prefación al Libro de los sermones o homilias en la lengua castellana y la indica general quechua. Lima 1648, reed. en Colección de libros y documentos referentes a la Historia del Perú. t. XI, Lima 1918, pp. 59-98 (v. esp. pp. 74 y ss.). P. D u vi o l s se ha hecho eco de ello en La lutte. .., p. 153. Sobre la biografía de F. de A vi 1 a, v. el estudio de P. D u vi o 1 s en Dioses y hombres..., pp. 218 y ss.

20) Una muestra de pleitos contra doctrineros desde 1600 , donde se incluyen los que atañen a visitadores de idolatrías, así como su valoración, 
$Y$ hay que detenerse en el hecho de que muchos doctrineros empezaran a verse envueltos en pleitos ante el tribunal eclesiástico porque es lo que puede explicar la reacción que supone la denuncia y persecución de las idolatrías de los indios. Con estos pleitos, en la primera década del siglo XVII los curas pasaron a encontrarse en una situación mucho más comprometida que anteriormente, cuando las quejas contra ellos existían pero de manera más generalizada, no personalizadas ante un tribunal de justicia.

Los enfrentamientos mencionados $\mathrm{y}$, sobre todo, los procesos judiciales - de los que a veces sólo se sabe que existieron - proporcian una dimensión nueva a la historia de la extirpación de las idolatrías en el siglo XVII, reduciendo el valor relativo de otras causas aducidas hasta el momento y centrando la razón que la originó en el ámbito americano. Pero para llegar a explicar la agudización de esos conflictos entre los curas de indios y otros sectores de la sociedad colonial, hay que prestar atención a la evolución de algunos aspectos de estructuras básicas como son las demográficas y las sociales.

II. Los cambios demográficos y sociales

A comienzos del siglo XVII la población indígena de Perú continuaba su proceso de declive que había comenzado con la Conquista. No había alcanzado aún el punto más bajo al que Ilegaría años más tarde, pero seguía un descenso constante si bien con ritmos que tendían a disminuir. En esta línea evolucionaban las regiones en las que se localizaba, hacia 1610 , la aparición de la denuncia de las idolatrías y la expansión de su persecución: la costa y la sierra norte, y la costa y la sierra central. La población en estas regiones descendía de acuerdo con las siguientes cifras ${ }^{22}$.

se encuentra en mi trabajo "Doctrineros de indios y economía en Perú. 1600-1630", actualmente en prensa en la revista Allpanchis, de Cuzco.

21) Noble D. C o o k, The Indian Population of Peru, 1570-1620. (Ph.D. Univ. of Texas Austin, 1973) Ann Arbor 1973, p. 304. Cfr. la valoración de los datos que hace el propio autor en p. 239. Las cifras absolutas 


\begin{tabular}{lccccccc} 
& 1570 & $\begin{array}{c}\text { Descenso } \\
\text { anual (\%) }\end{array}$ & 1590 & $\begin{array}{l}\text { Descenso } \\
\text { anual (\%) }\end{array}$ & 1600 & $\begin{array}{c}\text { Descenso } \\
\text { anual (\%) }\end{array}$ \\
$\begin{array}{l}\text { Costa } \\
\text { Norte }\end{array}$ & 80.123 & -2.38 & 49.975 & -2.11 & 40.449 & -1.95 \\
$\begin{array}{l}\text { Costa } \\
\text { Central }\end{array}$ & 128.820 & -2.28 & 82.044 & -1.92 & 67.710 & -1.73 \\
$\begin{array}{l}\text { Sierra } \\
\text { Norte }\end{array}$ & 209.057 & -1.24 & 163.366 & -1.11 & 146.274 & -1.10 \\
$\begin{array}{l}\text { Sierra } \\
\text { Central }\end{array}$ & 240.604 & -1.43 & 180.992 & -1.29 & 159.071 & -1.27 \\
& & & & & & \\
Costa & 33.263 & -1.79 & 27.787 & -1.64 & 23.578 & \\
$\begin{array}{l}\text { Norte } \\
\text { Costa }\end{array}$ & 56.942 & -1.56 & 48.715 & -1.40 & 42.329 & \\
$\begin{array}{l}\text { Central } \\
\text { Sierra } \\
\text { Norte }\end{array}$ & 131.034 & -1.07 & 117.737 & -1.03 & 106.125 & \\
$\begin{array}{l}\text { Sierra } \\
\text { Central }\end{array}$ & 140.052 & -1.23 & 123.776 & -1.19 & 109.801 & \\
\hline
\end{tabular}

De manera general se observa que, a comienzos del siglo XVII, aunque con cierta tendencia a disminuir, las tasas medias anuales de descenso de población se mantenían bastante altas. Sin embargo, si se observa la evolución de ciertos repartimientos donde se hallaban las doctrinas de los curas que intervendrían de manera más activa en el inicio de las campañas de extirpación, se notan algunos cambios que difieren de las tendencias mostradas más arriba y que resultan muy significativos. Tomemos, así, Huarochirí, donde se encontraban San Damián (cuyo doctrinero era F. de Avila), San Pedro de Casta (F. de Avendaño) y Santiago de Carampona (Luis de Mora y Aguilar), los dos repartimientos de

son de N. D. C o o k, pero la elaboración de las tasas es de mi responsabilidad.

V. también del mismo autor, «La población indígena en el Perú colonial», en: Anuario del Instituto de Investigaciones Hastóricas, no 8. Rosario 1965, pp. 73-1 10 . 
Conchucos, donde se incluía la doctrina de Corongo, y Siguas y Ocros (relacionados todos con Rodrigo Hernández Príncipe) y Chinchaycocha, comprendiendo la doctrina de Los Reyes (que tenía de doctrinero a Alonso Osorio). Los datos correspondientes a estos repartimientos $\operatorname{son}^{22}$ :

\begin{tabular}{|c|c|c|c|c|}
\hline & Años & $\begin{array}{l}\text { Número de } \\
\text { tributarios }\end{array}$ & $\begin{array}{c}\text { Descenso } \\
\text { medio anual } \\
\%\end{array}$ & $\begin{array}{c}\text { Población } \\
\text { total }\end{array}$ \\
\hline Huarochirí & $\begin{array}{l}1575 \\
1591 \\
1602\end{array}$ & $\begin{array}{l}1.812 \\
1.737 \\
1.481\end{array}$ & $\begin{array}{l}-0.28 \\
-1.46\end{array}$ & $\begin{array}{c}12.057 \\
\overline{9.097}\end{array}$ \\
\hline Chinchaycocha & $\begin{array}{l}1577 \\
1602 \\
1609 \\
1630\end{array}$ & $\begin{array}{l}1.912 \\
2.176 \\
1.750 \\
1.534\end{array}$ & $\begin{array}{c}0.5 \\
-3.16 \\
-0.47\end{array}$ & $\begin{array}{c}10.737 \\
11.073 \\
- \\
-\end{array}$ \\
\hline Siguas & $\begin{array}{l}1575 \\
1602\end{array}$ & $\begin{array}{l}242 \\
161\end{array}$ & -1.52 & $\begin{array}{l}1.213 \\
1.000\end{array}$ \\
\hline $\begin{array}{l}\text { Conchucos } \\
\text { Pardave }\end{array}$ & $\begin{array}{l}1575 \\
1593\end{array}$ & $\begin{array}{l}873 \\
668\end{array}$ & -1.5 & $\begin{array}{l}5.706 \\
3.670\end{array}$ \\
\hline Conchucos Mori & $\begin{array}{l}1575 \\
1592 \\
1594\end{array}$ & $\begin{array}{l}760 \\
755 \\
746\end{array}$ & $\begin{array}{l}-0.03 \\
-0.6\end{array}$ & $\begin{array}{c}4.759 \\
4.854 \\
-\end{array}$ \\
\hline Ocros & $\begin{array}{l}1575 \\
1597 \\
1599 \\
1603 \\
1615\end{array}$ & $\begin{array}{l}987 \\
818 \\
824 \\
560 \\
458\end{array}$ & $\left\{\begin{array}{c}-0.85 \\
0.36 \\
-10.1 \\
-1.68\end{array}\right.$ & $\begin{array}{c}4.458 \\
- \\
- \\
1.864 \\
-\end{array}$ \\
\hline
\end{tabular}

Partiendo de lo precario de los datos disponibles, se puede comprobar que hacia 1600 la tendencia de la población, expresada en número de tributarios, cambia sustancialmente con respecto a años anteriores en Huarochirí, Chinchaycocha y Ocros, mientras que en el resto de los casos el cambio más fuerte parece situarse antes, aunque existe el inconveniente de la falta de datos para la década de 1600. En efecto, en Huarochirí, con S. Damián, S. Pedro de Casta y Santiago de Carampoma, se pasó de

22) N. D. C o o k, The Indian ..., pp. 351,352, 258 y 359. De nuevo, los cálculos de las tasas son de mi responsabilidad. 
$-0.28 \%$ de descenso medio anual entre 1575 y 1591 á $-1.46 \%$ entre 1591 y 1602 . Pero mucho más espectacular que éste es el cambio que tuvo lugar en Ocros, que llegó a tener una tasa positiva entre 1597 y 1599 de $0.36 \%$ para pasar a descender a un ritmo de $-10.1 \%$ anual entre 1599 y 1603 , y de $-1.68 \%$ entre 1603 y 1615 . En Chinchaycocha, de 1577 a 1602 el número de tributarios aumentó a una tasa media al año de $0.5 \%$, para descender bruscamente entre 1602 y 1609 a un ritmo de $-3.16 \%$ anual y a $-0.47 \%$ entre 1609 y 1630 . De Siguas sólo se sabe que bajó a $-1.52 \%$ entre 1575 y 1602 , lo mismo que en Conchucos Pardave entre 1575 y 1593. Sin embargo, en Conchucos Mori nuevamente se observa un cambio violento de tendencia hacia $1592 / 4$, pasando de una evolución casi estacionaria a un descenso de $-0.6 \%$ anual.

Sobre la base de estos rasgos en la evolución de la población indígena, entre 1607 y 1613 se produce el primer grupo de pleitos que afecta a los curas que ocuparán enseguida un papel destacado en la primera campaña de idolatrías: Avila, Avendaño, Hernández Príncipe, Osorio y Mora y Aguilar. Las quejas fundamentales que dieron lugar a estos procesos judiciales eran - en los casos conocidos - de carácter económico y resulta inevitable relacionarlas con el descenso de población de las doctrinas. Derivándose de este último, la capacidad de los indios para satisfacer las exigencias de los doctrineros, al tiempo que el resto de las impuestas por otros sectores sociales de la colonia, se veía reducida considerablemente y la consecuencia era la aparición de conflictos entre las partes que se disputaban el excedente indigena o entre los propios indios y alguna de aquéllas partes, al defenderse los primeros de las exacciones que se les imponía.

Los repartimientos cuyos datos se han ofrecido han sido seleccionados por su significación con respecto al inicio de las campañas antiidolátricas, pero no hay que olvidar que el descenso de la población era generalizado y constante. Por ello no es de extranar que la iniciativa tomada por los curas de las doctrinas mencionadas más arriba fuera seguida de inmediato por otros de otras doctrinas diferentes que se hallaban en situacionaes notablemente parecidas a las de los primeros.

Junto a los cambios demográficos y sus consecuencias, están 
las transformaciones que tienen lugar en la estructura social indígena también desde la Conquista. Estas se derivan de la implantación del sistema colonial y afectan, a su vez, al funcionamiento de algunos elementos dentro del mismo sistema. Entre todas las que ocurren hay una, en particular, que interesa al papel del cura de indios y es la que sufre el cacique en su representación social y económica; el cura, por su parte tendrá una participación importante en esta transformación. Este cambio sucede a largo plazo y ya se han apuntado algunos de los pasos por los que transcurre su evolución desde el siglo XVI al XVIII ${ }^{23}$.

En un principio, conservando funciones de las que le correspondían desde la época prehispánica, el cacique continuó siendo tras la Conquista "... .el representante de su comunidad y el guardián de las normas sociales que regulaban las relaciones entre los miembros de la sociedad ... arbitrada las disputas de asentamiento entre los miembros de su grupo social, velaba por el mantenimiento de sus ritos y respaldaba las demandas de bienes y recursos hechas por los miembros más débiles o menos prósperos.... ${ }^{24}$. Aprovechando esta preeminencia del cacique con respecto a su comunidad, el sistema colonial, mediante su legislación, lo concibió como «... el agente encargado de extraer el trabajo y los bienes de la población india para el uso español. ..." 25. A cambio de ello, se le permitió conservar algunos de los privilegios sociales y políticos de que disfrutaba bajo el Imperio Inca, añadiéndosele otros específicamente coloniales ${ }^{26}$.

El resultado era contradictorio y el cacique estaba sujeto "a fuerzas complejas y opuestas» ${ }^{27}$. Por un lado, el sector colonizador que le exigía que fuese eficaz en su papel de recaudador del excedente indígena $y$, por otro, los intereses de su propia comunidad, que se suponía que debía defender. En este contexto, el

23) K. S p a 1 di n g, "El kuraka y el comercio colonial», en:De indio a campesino. Lima 1974, pp. 31-60 (v. esp. p. 32 y ss.).

24) Ibid., p. 36.

25) Tid., p. 57.

26) Ibíd. pp. 37-8 y N. W a c h t e l, Los vencidos. Los indios del Perú frente a la conquista española (1530-1570). Madrid 1976, p. 187 (ed. francesa 1971).

27) N. W a ch te 1, ibid. 
cacique participaba en el juego económico de la colonia adoptando papeles muy variados y si bien es verdad que, en general, parece que intervino en beneficio de la comunidad, hay dudas de que fuera siempre así. En cualquier caso, su intervención tendía a reforzar su posición predominante en la comunidad 28 .

En esta situación general, desde finales del siglo XVI, la presencia de algunos representantes de la autoridad española, como por ejemplo, el corregidor y el cura, comenzaron a socavar las funciones del cacique. Refiriéndonos concretamente al segundo, a pesar de que el enfrentamiento que más se ha destacado entre el cura y el cacique ha sido el que tiene lugar en el terreno religioso, en la medida en que el cacique era el encargado de velar por el mantenimiento de los ritos indígenas, no es ése el único plano en que el enfrentamiento tiene lugar $y$, de todas formas, el plano religioso se entremezcla con el económico, de manera que su distinción se hace difícil ${ }^{29}$.

En efecto, el cacique era el elemento al que el sector colonizador reconocía la competencia de "administrar» los recursos de la comunidad de acuerdo con sus propias necesidades y con las que le fueran planteadas por los colonizadores. Era, por decirlo así, un intermediario reconocido y privilegiado en virtud de su ascendiente sobre la comunidad. Pero con el incremento de la participación del cura en la economía, sobre todo con su acceso a los recursos indígenas, el cacique encontró un fuerte competidor que, a veces, no iba a reconocerlo como a tal intermediario ni a respetar su poder. Por el contrario, el cura acudiría directamente a la comunidad a por su cuota de excedente - extralimitando lo legislado, desde luego -, sorteando la figura del cacique. $Y$ esto

28) K. S p a 1 d i n g, op. cit., pp. 47 y ss. y 58; misma autora, «Los escaladores sociales: patrones cambiantes de movilidad en la sociedad andina

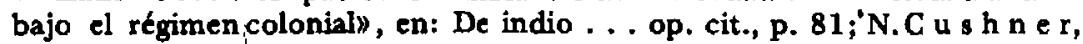
Lords of the Land. Sugar, Wine and Jesuit Estates in Coastal Peru, 1600-1767. New York 1980, pp. 15 y ss. Por otra parte, N. W a c h t e l, op. cit., pp. 187-195 tiende a pensar que, en términos absolutos, el cacique perdió poder en relación con la comunidad.

29) L. Mi 11 o n es, "Religión y poder en los Andes: Los curacas idólatras de la Sierra Central», en: Cuadernos, no 24-25, CONUP. Lima 1977, pp. 73-87. Aun con reparos que hay que hacer al párrafo, v. también $\mathbf{K}$. S p a l d i n g, "La red desintegrante», en: De indio. . . , op. cit., p. 117. 
iba a ocurrix antes de que ambos se enfrentaran abiertamente por el tema de las idolatrías.

En los pleitos existentes entre curas y comunidades, representadas frecuentemente por sus caciques - o entre curas y caciques que decian representar a sus comunidades, incluyendo el del mismo F. de Avila -, se pueden observar los mecanismos utilizados por los doctrineros para tener acceso directo al excedente indígena. Entre ellos se encuentran:

- apropiación de productos, en general, sin pagarlos ${ }^{30}$;

- llamar por padrón a los indios en misas y festividades para recoger ofrendas ${ }^{\mathbf{3 1}}$;

- imponer cantidades de productos y dinero para ser ofrecidas por los indios en las sepulturas de sus difuntos en el día de Todos los Santos ${ }^{32}$;

- imponer castigos, físicos y monetarios, por faltas en la práctica religiosa católica ${ }^{33}$;

- apropiarse del producto de los bienes de las cofradías ${ }^{34}$;

- excederse en la prestación de indios de mita y utilización de fuerza de trabajo indígena sin remunerar ${ }^{35}$.

30) Como ejemplos se pueden citar: Pleito contra F. de Avila (S. Damián- 1607), Archivo Arzobispal de Lima (en adelante A.A.L.), Sección Capítulos, 1; Pleito contra Luis de Mora y Aquilar (Pariamarca- 1617), A.A.L. Capítulos, 3; Información promovida por Bartolomé Lobo Guerrero «acerca de la costumbre que tienen de entrometerse en las jurisdicciones eclesiásticas) los religiosos doctrineros (1612), Archivo General de Indias, Lima 301; Id. id. en razón de los «excesos que los religiosos de las órdenes hacen en las doctrinas que estan a su cargo" (1614). Archivo General de Indias. Lima 301. Los dos últimos documentos sirven como ejemplos también para las notas $29,30,31$ y 33 .

31 ) Por ejemplo: Pleito contra Alonso Mejía (Llacta -1614-19). A.A.L., Capítulos, 3; Pleito contra Gonzalo Guerrero de Luna (Cochamarca- 1615). A.A.L., Capitulos, 3.

$32)$ Como ejemplos: Pleitos contra F. de Avila (S. Damián - 1607). A.A.L., Capítulos, 1; Pleito contra Juan Gutiérrez de Aguilar (Cajatambo1618). A. A.L., Capítulos, 3.

33) Así, los casos siguientes: Pleito contra Diego Alonso de Rojas (S. Juan de Machaca- 1604). A.A.L., Capítulos, 1; Pleito contra Luis Mejía (Chaclla- 1622). A.A.L., Capítulos, 4.

$34)$ V. Pleito contra Juan Núñez de Prado (Cinga- 1626-9). A.A.L., Capítulos, 6.

$35)$ Pleito contra Diego de Alvarado (Piscobamba- 1610). A.A.L., Capitulos, 2; Pleito contra Luis Antonio Luis López (Huacaybamba- 1622). A.A.L., Capítulos, 4. 
Se puede observar que había métodos ejercidos en razón de la coacción física, como los castigos o algunas apropiaciones de productos, $y$ otros en que predominaban relaciones de control religioso, como el aprovechamiento de las cofradías o las ofrendas de Todos los Santos. En este último caso, por cierto, el cura contemporizaba con prácticas religiosas indígenas.

Por todos estos conductos el cura eludía la figura del cacique como intermediario entre la comunidad y el sector colonizador y demostraba no necesitar de su poder, ejercido mediante las relaciones de parentesco. Al mismo tiempo, absorbía mayor cantidad de excedente, perjudicando a la comunidad en sus obligaciones estipuladas por la legislación y al mismo cacique, en la medida en que él mismo acumulara una parte del mismo. Todo ello explica la aparición de los caciques en los pleitos y, en última instancia, la agudización de los conflictos, si se recuerda la evolución demográfica expuesta más arriba.

Con estas transformaciones que ocurren en el mundo colonial, aparecen los pleitos que a continuación se exponen y que, en mi opinión, apoyan la hipótesis que ya expuse. Al pasar a su estudio, puede ser útil establecer una clasificación de los mismos, atendiendo al desarrollo de la primera campaña extirpadora de la idolatría, que es la que este artículo cubre. Así, pueden considerarse: $1^{\circ}$ ) Los casos que tienen lugar antes de la denuncia pública de 1609: Francisco de Avila y Fernando de Avendaño. $2^{\circ}$ ) Los que afectan a doctrineros antes de que fueran nombrados Jueces Visitadores de Idolatrías: además de los dos anteriores, Rodrigo Hernández Príncipe, Luis de Mora y Aguilar y Alonso Osorio. $\left.3^{\circ}\right)$ Los que ocurren después de 1614-16, con la generalización de la campaña.

II. Los procesoscontra los doctrineros

El primero, más interesante $\mathrm{y}$, afortunadamente, mejor conservado de los pleitos que aquí interesan es el de los indios de $\mathrm{S}$. Damián de Huarochirí contra su doctrinero, Francisco de Avila, 
que data de $1607^{36}$. Avila, como ya se sabe, fue objeto de una denuncia, previa a la suya de las idolatrías, por parte de sus indios ante el Juzgado Eclesiástico de Lima. Este hecho contradice lo que él mismo narraría más tarde en el sentido de que fue él quien primeramente denunció las idolatrías de los indios, en Diciembre de 1609 , y que los indígenas, después y como venganza, lo acusaron ante el Provisor del arzobispado ${ }^{37}$. Cuesta trabajo creer que Avila olvidara algo tan importante para él como el desarrollo cronólogico de estos hechos, máxime cuando demostraba recordar tan bien otros detalles. Si, en lugar de haber olvidado, en 1648 Avila hubiera mentido, habría que sospechar fundadamente que quizás fuese él quien actuó vengándose de los indios.

En cualquier caso, el pleito de Avila resulta el paradigma de lo que iba a ocurrir con otros doctrineros, con la ventaja para él de que fue quien tuvo la oportuna ocurrencia, notable en cierto sentido, de reaccionar cuando se vio apurado por el desarrollo del pleito planteando ante el arzobispo de Lima la existencia de prácticas idolátricas en su propia doctrina. Avila llevaba 14 años de cura en Huarochirí, había recogido la tradición oral que hoy conocemos como "Dioses y hombres de Huarochirí" en 1598, donde se habla de Pariacaca y Chaupiñamoc, cuyos ritos son precisamente los que denunciaría ${ }^{38}, y$, como se descubrió en el pleito, permitía algunas de las prácticas religiosas en su doctrina; sin embargo, esperó, aparentemente de manera inexplicable, a Agosto de 1608 para "descubrir» la idolatría y a Diciembre de 1609 para denunciarla públicamente ante el arzobispo. ¿Qué sen. tido tiene este hecho? Si se estudia con detenimiento el desarrollo del pleito se observan determinadas coincidencias que pueden resolver la pregunta.

36) A.A.L., Capítulos, 1. Cfr. mi artículo «El pleito de los indios. ..» op. cit. - Salvo que se exprese lo contrario, el relato de los hechos se basa en el documento referido.

37) F. de A v i 1 a, Prefación. . ., en: Colección de libros y documentos. .., op. cit., pp. 64 y ss. P. D u vi o 1 s en: La lutte. .., op. cit. p. 148, recoge los datos más destacados de la narración.

No deja de ser llamativo que $\mathrm{F}$. de $\mathrm{A}$ v i l a se atreviera a publicar, con la aprobación del arzobispo, una versión inexacta de los hechos que podía ser fácilmente desmentida con el expediente que se conservaba en el propio archivo del arzobispado.

38 ) Dioses y hombres..., op. cit. 
F. de Avila fue acusado en Septiembre de 1607, antes de que el problema de las prácticas religiosas indigenas se hubiera planteado en el nivel de las doctrinas, salvo para llevarlo como preocupación a los Concilios Provinciales y a los Sínodos. Los indios de S. Damián, representados por sus caciques, se quejaban de que Avila había llevado a cabo exacciones y perjuicios diversos a la comunidad desde hacía varios años. Como primera instancia Avila fue encarcelado en el arzobispado y, desde la cárcel, solicitó estar presente en su doctrina cuando se efectuaran las informaciones sobre el caso y, además, que las informaciones las realizara el racionero Baltasar de Padilla que, al parecer, se hallaba como visitador eclesiástico en Huarochirí. Pero, mientras que Avila conseguía la fianza para poder salir de la $\operatorname{cárcel}^{39}$, y antes de que Padilla llegase a la doctrina, algunos de los indios acusadores comenzaron a ser visitados por el P. Andrés de Terrazas, doctrinero de Chorrillo, un tal don Juan dé Sangüesa y un indio llamado Cristóbal Choquecasa, entre otros, en Febrero y Marzo de 1608, con objeto de recabar de ellos declaraciones de retractación de sus acusaciones, lo cual consiguieron en algunos casos. Hay que pensar que estas visitas, al margen de los cauces legales previstos, se hacían a instancias del propio Francisco de Avila y el hecho de que se retractaran hace sospechar que las declaraciones pudieron ser obtenidas mediante algún tipo de estímulo material o de coacción. De cualquier forma, las retractaciones no fueron completas sino a medias. En ellas los indios siguieron manteniendo que su cura había hecho uso de muchos recursos económicos de la comunidad y que aún les debía algunas cosas, aclarando que bastantes de los «servicios» que le habian hecho fueron sólo como favor.

Entre Abril y Mayo de 1608 el visitador B. de Padilla realizó sus trámites en la doctrina, limitándose básicamente a buscar la ratificación de las declaraciones de retractación obtenidas en su ausencia, búsqueda que no pudo cubrir todas las que Terrazas,

39) La fianza fue presentada por un tal Juan Delgado de León, cuyo nombre y primer apellido coinciden con los del doctrinero de S. Sebastián de Huaraz que después sería visitador de idolatrías. Más adelante se examinará un pleito contra este doctrinero. Cabe la duda de si se trataba de la misma persoria. 
Sangüesa y Choquecasa habían logrado. En el auto final de sus trámites Padilla destacaba el hecho de que los indios desistían de continuar el pleito y, curiosamente, exhortaba a Avila a que:

\begin{abstract}
"I... sobre este caso no los maltrate [a los indios] ... ni les ponga demanda .... atento a que son indios incapaces y de poco entendimiento, so pena que será castigado por ello; y el dicho doctor, estando presente, dijo que así lo guardará y cumplirá ...."
\end{abstract}

Tras esta exhortación, el visitador remitió los autos al Provisor para que los concluyera y, sólo tres meses más tarde, en Agosto de 1608 , sin que se hubiera pronunciado sentencia, Avila "descubría" la idolatría de los indios, gracias a la confidencia de uno de ellos llamado Cristóbal Choquecasa, según su propia narración de $1648^{40}$. Avila no explicó entonces nada acerca de este personaje. Hoy podemos suponer que era alguien en quien debía tener confianza desde hacía tiempo, pues se trataba precisamente de una de las personas que se había dedicado a recabar retractaciones de los acusadores antes de que el visitador llegase a la doctrina.

Aún con el pleito sin sentencia, hallándose incurso en él, Avila fue elevado en 1608 a un beneficio de la ciudad de Huánuco, desligándose así, al menos sobre el papel, de su doctrina; sin embargo, continuó en ella y, por el momento, no pudo tomar posesión de su nuevo beneficio debido a un retraso del anterior ocupante en abandonarlo. No se sabe nada de sus actividades hasta Junio de 1609 en que, hallándose todavia en Huarochirí, escribió al P. Diego Alvarez de Paz, S. J., solicitando algunos padres de la Compañía para la misión antiidolátrica en la doctrina que ya había comenzado ${ }^{41}$.

Algún tiempo después el pleito continuaba abierto y en Septiembre del mismo año un nuevo fiscal eclesiástico en Lima desempolvó el expediente dándole un nuevo giro al mismo. Primeramente requirió la confesión de Avila sobre las acusaciones de los indios, trámite que no se había cumplimentado aún tras dos años de pleito, y al negar Avila rotundamente uno por uno todos los capítulos, el fiscal renovó la acusación criminal contra el cura.

40) F. de A vil a, Prefación. ., op. cit., pp. 63-4.

$41)$ Dioses y hombres. .., op. cit., pp. 245-7 y 248. 
Con su negativa, Avila había entrado en contradicción con las retractaciones de los indios acusadores que habían mantenido una parte de sus denuncias - aunque hubieran desistido de seguir el pleito - pero, sobre todo, contradecía el hecho de que, delante del visitador Padilla, él mismo había procedido a compensar económicamente alguna de las reclamaciones de los indios, admitiendo con ello la veracidad de las quejas. A estas alturas del pleito podría decirse que, enfrentado ya abiertamente en Huarochirí con los indios por el tema de las idolatrías, Avila se hallaba obcecado e incapaz de reconocer ninguna falta suya contra aquéllos ante el Tribunal Eclesiástico.

Como resultado de la acusación del fiscal se procedió a un nuevo interrogatorio, ahora sólo a dos indios, en el que uno de ellos declaró que había sido inducido por otros indios a presentar capítulos contra el cura, y el otro, cuyo nombre en realidad no aparecía entre los capitulantes en el pleito, manifestó que su personalidad habia sido suplantada y que él no había acusado a Avila. Con ello el final del proceso no parecía plantear problemas, a menos que se siguiera buscando al resto de los indios que en un principio se quejaron del doctrinero y que aún no habían declarado.

En estas condiciones, Avila organizó el traslado masivo de pruebas de las idolatrías indigenas a Lima en Diciembre de 1609, compuestas por seis cargas de dos quintales cada una, en las que iban algunas momias de los antepasados de los indios, quizás las mismas sobre las que éstos depositaban productos y dinero con conocimiento de Avila ${ }^{42}$. Merece recordarse que, precisamente en una de las declaraciones de retractación que sirvió de base para la defensa y final absolución del cura, Martín Puypurocci, principal de Santiago de Tumna, manifestaba en Marzo de 1608:

«... y en lo que toca a los Todos Santos, los indios e indias no ponen sobre sus sepulturas más que dos reales cada uno y el maiz y papas que quieren, sin que el dicho doctor lo mida, si no es estos Todos Santos pasados que dijo que pusiese cada uno de los casados y viudas medio almud de papas pues que le le santaban [sic] que hacía poner cuatro almudes del uno y del otro. ...)

$42)$ F. de Avila, Prefación ..., p. 74. 
Ya en Lima, el 13 de Diciembre, Avila pronunció un solemne sermón en la catedral contra la idolatría y el 20 del mismo mes llevó a cabo una espectacular quema de idolos, acompañándola de la confesión de un sacerdote indígena sobre las prácticas religiosas de los indios en la Plaza de Armas de la ciudad. El día 24 se producía la sentencia absolutoria en el pleito que los indios de su doctrina le habían puesto hacía ya más de dos años ${ }^{43}$. Era un paso casi obligado dado el curso que habían seguido los acontecimientos.

Resulta imposible recoger en estas páginas la gran cantidad de detalles y matices de interés contenidos en el expediente de 144 folios. Sin embargo, tras reconstruir la evolución de los hechos entre 1607 y 1609 , es necesario detenerse en algunos puntos que vinculan este juicio con otros posteriores. El primero es el de la naturaleza de las acusaciones de los indios contra Avila. Se trata de más de cien capítulos que afectan principalmente a materias económicas, como son: la apropiación de gran cantidad de productos - papas, maiz, quina, chochoca, etc. . - sin pagarlos; el uso de gran cantidad de mano de obra indígena, en diversos trabajos, sin remunerar; la utilización de caballos de los indios para cargas de mercancías en diferentes trayectos; la apropiación de bienes de indios difuntos; la apropiación de materiales de viviendas de indios, tras una reducción, para la construcción de su casa en Lima; el impago de deudas por el mantenimiento de su madre que vivió durante un tiempo en la doctrina, etc... En las retractaciones muchos de estos capítulos se mantuvieron, si bien los indios que declararon redujeron su volumen y especificaron que muchos de los servicios realizados al cura lo habían sido por amistad y sin esperar nada a cambio; incluso una de las deudas reclamadas por los indios, que ascendía sólo a siete pesos y medio ensayados, fue cancelada en presencia del visitador Padilla, como ya se mencionó.

Por otra parte, la intervención, al margen de los autos del visitador, de Sangüesa, Terrazas, Choquecasa y otros, las retractaciones de indios que no habían acusado a Avila inicialmente

43) Ibíd., pp. 74-5. El sermón se publicó en F. de A vil a, Tratado de los Evangelios que nuestra madre la Iglesia. . . Lima 1648. 
mientras que otros que sí lo capitularon no se retractaron nunca $y$, finalmente, la eliminación en el expediente de parte de los capítulos - los que hacían referencia a las relaciones de Avila con indias de la doctrina y a la existencia de un hijo del cura que vivía con él - que hizo necesaria la falsificación de la firma de los indios que los habian presentado, obliga a ponerse en guardia ante la eventualidad del uso de testigos falsos y de declaraciones manipuladas, tanto por parte de los indios como del doctrinero ${ }^{44}$. De cualquier forma, tanto en este caso como en algunos de los que siguen, donde este tipo de problemas se vuelve a presentar, parece quedar clara la permanencia de las acusaciones de los indios por encima de matizaciones.

De todo lo observado cabe deducir: $1^{\circ}$ ) Que avila no se atenia a la verdad cuando en 1648 narró en la "Prefación ..." su versión del inicio de su denuncia y que no fueron, por tanto, los indios los que se vengaron de él ${ }^{45}$. Si no cabe acusar al cura de haberse vengado él mismo, es un hecho, al menos, que las cosas ocurrieron al revés. $2^{\circ}$ ) Que Avila mantenía actividades económicas en su doctrina que sobrecargaban el peso tributario a los indios, al margen de lo previsto en el sistema colonial. $3^{\circ}$ ) Que en el desarrollo del pleito se registraron ciertas irregularidades a las que no fueron ajenas las autoridades eclesiásticas y, desde luego, el visitador Padilla, quien dio por buenas las declaraciones conseguidas, antes de su llegada, por personas presumiblemente próximas al acusado.

Junto a F. de Avila, el más conocido Juez Visitador de Idolatrías en las campañas del siglo XVII quizás sea Fernando de

44) Por no abrumar con la gran cantidad de nombres indígenas que aparecen en el pleito, resumiré diciendo que, entre caciques, indios principales y otros, se contabilizan 26 nombres de indios acusadores, mientras que 29 firmaron retractaciones. De todos ellos, sin embargo, sólo 6 coincidían en las dos relaciones, cuatro de los cuales eran caciques. No se retractaron, por tanto, 21 indios, entre ellos un cacique. Tras las retractaciones, los indios no coincidían en explicar las causas de las denuncias. Algunos decían temer la instalación de un obraje en la doctrina por Avila y el corregidor, en colaboración, mientras que otros establecían la relación entre Avila y el encomendero. Esta falta de coincidencia no deja de ser sospechosa.

45) La sospecha de esta discordancia la tuvo P. D u vi o l s basándose en la referencia que había dado del pleito. J. T. Polo en 1906. Cfr. La lutte. .., op. cit., p. 149 , nota 9. 
Avendaño ${ }^{46}$. Sobre él no existe un documento tan completo como el de Avila, pero se sabe que tuvo un pleito similar.

Siendo doctrinero de San Pedro de Casta, en Huarochiri, en 1609, antes de Pascua, iba a recibir la visita eclesiástica de Gil Guerrero de Luna, visitador para aquel distrito, y con tal ocasión presentó un escrito al Provisor del arzobispado de Lima por el que se descubre la existencia de un pleito interpuesto por los indios de su doctrina contra él. En dicho escrito explicaba que había tenido que ir a Lima a defenderse de "los capítulos que me pusieron los indios de los pueblos de San Juan y San Lorenzo de mi doctrina" y que, estando en Lima, había enfermado, por lo que pedía excusas de no poder estar presente durante la visita de Guerrero. Con su escrito, Avendaño presentaba certificados de tres médicos sobre su enfermedad y proponía, bien que la visita comenzase por otros doctrineros, bien que se iniciase después de Pascua, fecha para la que esperaba encontrarse repuesto ${ }^{47}$.

El que no se hayan conservado los capítulos, los autos ni la sentencia del caso - que, si se llegó a pronunciar, debió ser favorable a Avendaño, dada la carrera que después siguió - no resta importancia al conocimiento de su existencia y ésta sitúa al futuro Juez de Idolatrías en el contexto de los enfrentamientos entre curas e indios antes del comienzo de las campañas extirpadoras. La existencia de los pleitos contra Avila y Avendaño, entre otros que conocía el Tribunal Eclesiástico de Lima desde 1600 , como mínimo, confirma sencillamente que, antes de 1609 había graves confrontaciones entre doctrineros y las comunidades de sus doctrinas las cuales, unidas a otras condiciones favorables, ayudan a explicar la participación de éstos y otros curas en el movimiento que se iniciaría en al año siguiente.

Entre 1610 y la difusión de la primera campaña, que parece que tuvo lugar hacia mediados de esta década, existieron otros juicios contra algunos de los doctrineros que, con posterioridad, serían nombrados Jueces Visitadores de Idolatrías en dicha cam-

46) Cfr. P. J. A r r i a g a, Extirpación ..., op. cit., Prólogo y pp. 6, 7, 9, 21, 25, 62, 103, 108 y 117. Son muy conocidos sus: Sermones de los misterios de nuestra Santa Fe Católica. . Impugnanse los errores particulares que los indios han tenido. Lima 1649.

47) A.A.L., Capitulos, 1. 
paña, concretamente, Rodrigo Hernández Príncipe, Luis de Mora y Aguilar y Alonso Osorio.

Tras los dos ya mencionados, otro de los extirpadores de idolatrías más destacados de estos años no cabe duda que fue Rodrigo Hernández Príncipe ${ }^{48}$. Con 11 años como cura, aproximadamente, siendo doctrinero en Corongo, Conchucos, se vió envuelto en un pleito ante el Tribunal Eclesiástico, como consecuencia de unas acusaciones presentadas probablemente por españoles residentes en Siguas. Esto ocurría en Agosto de 1610, cuatro años antes de que fuese nombrado por el arzobispo Lobo Guerrero visitador de idolatrías ${ }^{49}$.

Las acusaciones se referían a que el cura vivía amancebado con una india de la doctrina y a que mantenía "tratos y contratos», poseyendo tornos y telares para fabricar tejidos, cordellates y sayales, vejando y molestando a los indios. La averiguación deI caso fue encargada al Ldo. Hernando Maldonado, visitador eclesiástico de la provincia de Conchucos, quien acudió a testigos españoles, hacendados y mineros de Siguas. Los testigos confirmaron que Hernández Príncipe daba mal ejemplo «con vicio y mujeres», que mantenía relaciones con una india a la que llamaba "la india del Padre», que tenía residiendo en su casa a familiares que daban trabajo a los indios y, sobre todo, que tenía un obraje en la doctrina en el que ocupaba "mucha cantidad de indios chicos y grandes». Hacía sólo dos meses y medio, como producto de este obraje, Hernández Príncipe había mandado a Lima una recua cargada de ropa por medio del sobrino de uno de los declarantes, un tal Bernardino Montoya.

Ante la averiguación del visitador, el arzobispo ordenó al cura comparecer en Lima y envió en "interin» a la doctrina a Francisco Rodríguez, colegial del Seminario de la ciudad. Esto debió ocurrir a finales de 1610 o a comienzos del año siguiente. A partir de este momento no se sabe qué dispuso Bartolomé Lobo Guerrero, ni tampoco consta que el pleito tuviera conclusión. Lo que sí se sabe es que, hacia 1615, Hernández Príncipe era doctri105.

48) Cjr. P. J. Arri a g a, Extirpación..., op. cit., pp. 54, 58, 62, 80 y

49) P. D u vi ol s, La lutte..., p. 157 no concreta la fuente ni la fecha exacta. El pleito está en A.A.L., Capítulos, 2. 
nero en Santo Domingo de Ocros, en Cajatambo, y desde allí fue nombrado Juez Visitador de Idolatrías, comenzando su participación en la campaña que ya estaba en marcha ${ }^{50}$. Evidentemente, por tanto, Hernández Príncipe había continuado su carrera como doctrinero después del pleito tenido en Conchucos.

Con relación al proceso hay que hacer notar que fueron espa. ñoles, no indios, los que se quejaron de la actividad económica del cura utilizando mano de obra de su comunidad y que es muy probable que la base de la disputa estribara en el acceso a su fuerza de trabajo.

Menos conocido que los ya citados como Juez Visitador de Idolatrías es Luis de Mora y Aguilar, uno de los primeros en las campañas del siglo XVII y del cual se conoce alguna de sus visitas iniciales ${ }^{51}$. De este doctrinero de Santiago de Carampoma se conserva únicamente la referencia, breve, de un conflicto que tuvo hacia 1611 con el cacique del pueblo, pero que complementa el conjunto de casos que estamos observando.

En dicha fecha Mora y Aguilar fue acusado, por medio del Protector de Naturales, de dar malos tratos al cacique principal y gobernador de la localidad, Don Martín Michuy, y a su mujer. La averiguación del caso se encargó al visitador eclesiástico Gil Guerrero de Luna quien, una vez concluidos los autos, demoró su entrega al Provisor del arzobispado, Feliciano de Vega, provocando la insistencia ante éste del Protector de los Naturales sobre la agilización del pleito. Vega pidió entonces a Guerrero de Luna la entrega de las informaciones, pero, si éstas llegaron a verse, desde luego no han llegado hasta nosotros, impidiendo conocer qué problema latía debajo de la agresión física de Mora y Aguilar al cacique $^{52}$. De cualquier forma, se trata de un caso más que añadir

50) P. J. A r r i a g a cn: Extirpación. .., p. 54, dice que antes de tener el título de Visitador - aunque seguramente con posterioridad al pleito que aquí se presenta -, hab ía obtenido licencia del arzobispo para ausentarse de su doctrina de Sto. Domingo de Ocros y actuar contra las idolatrías.

51) P. J. Arri a g a menciona en Extirpación ..., p. 9 a un visitador llamado Luis de Aguilar. P. D u vi o $1 \mathrm{~s}$ ha publicado «La visite des idolâtries de Concepción de Chupas", en: Journal de la Société des Americanistes, t. LV, no 2. Paris 1966, pp. 497-510, realizada por Mora y Aguilar.

52) A.A.L., Capítulos, 2. 
a la serie de enfrentamientos entre curas y caciques aunque, como se advirtió, este modelo no se reproduce siempre.

Un nuevo Juez Visitador de Idolatrías nombrado hacia mediados de la década de 1610 que se vió afectado por un pleito con anterioridad fue Alonso Osorio, acusado de tener actividades económicas en su doctrina de Los Reyes de Chinchaycocha ${ }^{53}$. Aunque al expediente le faltan algunos folios del comienzo, se puede deducir de su desarrollo que las quejas iniciales fueron presentadas por un tal Bachiller Manuel Gerónimo del Castillo y Montalvo, clérigo que vivía en la doctrina, y se referían a numerosas relaciones de Osorio con indias de la doctrina, asi como a su intervención en un activo comercio con los indios de diferentes artículos $^{54}$.

En cuanto a las relaciones con las indias, los interrogatorios practicados desvelaron que el $\mathrm{Br}$. del Castillo había intentado sobornar a una india para que declarara contra Osorio y así poder organizar las acusaciones en este tema. Es interesante notar que, al no acceder la india en cuestión, fue objeto de malos tratos físicos por parte de una negra propiedad de dicho Del Castillo.

Pero junto a estos falsos testimonios en el terreno sexual, sobre el asunto de las relaciones económicas se deduce del proceso que A. Osorio estaba involucrado en un tráfico de vino que, procendente de Lima, terminaba vendiéndose en una pulpería de la plaza del pueblo que regentaba una india y, también, en su propia casa, donde otra india vieja, que vivía con el cura y le hacía la comida, era la encargada de venderlo al por menor. Aunque este comercio se mantenía al menos desde hacía tres años y no se puede saber quiénes estaban relacionados con él en ese tiempo, en el momento del pleito el vino pertenecía al corregidor de la provincia, Don Juan Marmolejo, y se comercializaba por medio de un mercader llamado Pedro Bustillos y en la recua propiedad de un tal Cristóbal de Orellana. En Los Reyes los mayoristas del vino eran Alonso Osorio y los caciques y eran éstos últimos quienes lo hacían llegar a la pulpería de la plaza.

53) Cfr. P. J. Arri a ga, Extipación..., pp. 9, 23, 30, 36, 102 y 113.

54) A.A.L., Capítulos, 2. 
Alonso Pomavilca, indio fiscal de la localidad, que fue interrogado en varias ocasiones y que declaró sistemáticamente ignorar las actividades del cura, afirmaba no saber que Osorio fuera propietario del vino que se vendía en la pulpería, pero que sí sabía que la vieja que vivía con él compraba, vendía y bebía vino y también chicha. Pero no era sólo vino lo que Orellana transportaba hasta el pueblo, sino también "baúles, petacas ... y otras cosas", entre las que había tejidos y rosarios. Pomavilca, como antes, no sabía que el cura hubiera vendido paños "... para que las indias vayan a misa con la cabeza cubierta .... ni rosarios, pero sí aceptaba que Juan Osorio, el Viejo, padre de A. Osorio, y Cristóbal Orellana, durante una ausencia del cura a Lima, le habían entregado doce paños de naval, de los que vendió cuatro a ocho reales devolviéndoles los restantes, y quince docenas de rosarios, de las que vendió seis, a cinco reales cada rosario ${ }^{55}$.

En otra ocasión en que A. Osorio fue a Lima en compañía de Pomavilca, dejó por fiscal del pueblo a Santiago Capchacuri, indio cantor ladino, y fue a éste a quien $\mathrm{J}$. Osorio y Orellana dejaron 50 paños para que los vendiera, al parecer, al precio que los quisieren comprar. Capchacuri declaró que los había vendido y entregó dos veces 25 pesos, una vez a J. Osorio y Orellana juntos y otra sólo a Orellana. El mismo testigo declaró igualmente que, en esta ocasión había sido Pomavilca, se supone que a su vuelta de Lima, quien había vendido los rosarios.

Por otro lado, un tal Miguel Caxaricapa, fiscal del pueblo de San Pedro de Cacas desde hacía más de catorce años, declaró que en una ocasión - no se sabe si sería la misma que la anterior - en que partieron A. Osorio y Orellana a Lima, el último volvió y le entregó al testigo 80 paños de lienzo «menos que Ruán de poco menos que a vara cada uno" y también cuatro manojos de rosarios, con 24 más o menos cada uno. Caxaricapa vendió los paños a ocho reales y los rosarios a cinco reales la unidad, entregando la plata a Orellana.

Al margen del vino, paños y rosarios, en los interrogatorios a

55) No queda claro en las respuestas al fiscal las veces que actuó como intermediario en las ventas a los indios, pero, desde luego, parece que fue más de una. 
las indias envueltas en las pretendidas fornicaciones de A. Osorio, María Cutin, que negó las acusaciones que se imputaban al cura, declaró, sin embargo, que en una ocasión éste la había llamado, junto a otras indias, haciéndolas entrar en la cocina de su casa y, una vez allí, el fiscal del pueblo les habia repartido "seda de colores» para que la «derramasen» diciéndoles que era para Cristóbal de Orellana, huésped del Br. Osorio.

Según las precauciones adoptadas de cara al proceso, cuya información corrió a cargo del vicario de Vico y Pasco, Francisco Arroyo $\mathrm{Naharro}^{56}$, en el arzobispado se sospechaba que uno de los caciques del pueblo pudiera haber reunido a la comunidad, antes de comenzar los interrogatorios, advirtiéndola de no declarar en contra del cura. De ser cierta esta sospecha, es claro que existía complicidad entre los caciques, A. Osorio, los comerciantes $\mathrm{y}$, eventualmente, el corregidor, completándose una red casi perfecta. Por encima de los matices expresados, parece claro que A. Osorio estaba implicado en el negocio comercial, pues además de las conexiones que se intuyen en las declaraciones de los testigos, Orellana, el dueño de la recua, no sólo repartía la mercancía en la doctrina sino que guardaba su recua con los aparejos y las propias mercancías en la escuela donde Osorio enseñaba la doctrina a los muchachos indios, utilizándola como almacén.

Sin entrar en muchos otros detalles de interés en este grueso proceso, tras los interrogatorios Osorio fue encarcelado en el arzobispado de Lima. Sin embargo, al final del pleito, el Provisor, $F$. de Vega, lo absolvió de los cargos de venta de vino en la pulpería y del resto de las acusaciones, a pesar de las dudas que podían despertar las respuestas de los testigos, y únicamente fue condenado por la venta de vino en su casa y por la guarda de la recua de Orellana en la escuela a 30 pesos de a nueve reales, siendo restituido a su doctrina en Marzo de 1614.

Merece ser destacado el hecho de que no es, en esta ocasión, la comunidad ni los caciques quienes acusan al cura, sino otro cléri-

56) El propio Arroyo Naharro estuvo incurso en un proceso judicial, entre 1619 y 1621 , al exigir los beneficios de una capellanía, A.A.L., Capítulos, 4. 
go, probablemente deseoso de ocupar como titular la doctrina. Es por este deseo por lo que termina descubriéndose todo el montaje comercial tan bien organizado que llevaba funcionando años, a pesar de lo cual Osorio volvió como titular a la misma doctrina, en la que permaneció largo tiempo, mientras que era simultáneamente Juez Visitador de Idolatrías, a partir de 1615, aproximadamente.

De nuevo se detecta en este caso la importancia del pequeño grupo de personas que rodea a la figura del cura y que cumplía una función importante en su apoyo: el fiscal, un indio cantor, su padre. . . Por su parte, Gerónimo del Castillo también tenía una negra que intervino en el intento de forzar a las indias para que acusaran al doctrinero.

Alonso Osorio sería, a partir de su actuación como extirpador de la religión indígena, persona relativamente conocida, entre otras cosas, por volverse a ser envuelto en problemas judiciales. Citaré aquí un caso y reservo otro para más adelante por motivo de orden en el trabajo.

Continuando como cura en Los Reyes de Chinchaycocha, donde tenía como ayudantes a los padres Blas de Garagate y Saldaña, el primero de los cuales ya se mencionaba en el pleito de 1613, el fiscal eclesiástico acusó a Osorio en Junio de 1620 de haberse ausentado de su doctrina sin licencia y sin dejar sacerdote que administrara los sacramentos. Osorio se defendió alegando que sufría la "enfermedad de la piedra» desde hacía mes y medio, por lo que se habia obligado a venir a Lima, a pesar de lo cual fue condenado a 25 pesos y amonestación de pena mayor, ordenándosele el regreso inmediato a su doctrina. Osorio consintió en su condena y pidió prórroga de dos días para cumplir el regreso ${ }^{57}$.

Otro de los primeros Jueces Visitadores de Idolatrías nombrado también a mediados de la década de 1610 fue el $\mathrm{Br}$. Juan Delgado, cura de San Sebastián de Huaraz, quien en 1612 tomó parte en un pleito aunque, excepcionalmente, en esta ocasión el doctrinero no era el acusado sino el acusador ${ }^{58}$.

57) A.A.L., Capítulos, 4.

58 ) Cfr. P. J. A r riag a, Extirpación..., pp. 9, 13 y 20. V. también nota 39 supra. 
De los únicos folios que se conservan del expediente del juicio se saca la conclusión de que Juan Delgado y Juan Bautista Veintin(?) instigaron a los indios de la doctrina a presentar capitulos contra D. Pedro Espinosa y un tal Duarte, acusándoles de agraviarlos. No se puede colegir más de este documento, sino que en el proceso aparecía también un tal D. Fernando, cacique, y que, posiblemente, uno de los acusados debía ser eclesiástico, lo que explicaría la presencia del documento en el arzobispado. A pesar de no ser el doctrinero el acusado en este caso, el ejemplo es ilustrador de la participación de los curas en conflictos de diversa índole, siempre con la base de la explotación de los indios.

Los casos expuestos hasta aquí cubren dos etapas que hay que distinguir para mayor claridad del análisis y muestran, primeramente, como ya se ha insistido, la existencia de conflictos personalizados $y$ en forma de procesos judiciales entre distintos sectores sociales, afectando a curas doctrineros, antes del comienzo y la expansión de la primera campaña extirpadora y, en segun. do lugar, que todos los visitadores de idolatrías más conocidos de dicha campaña se vieron envueltos en estos pleitos ${ }^{59}$.

Los procesos que siguen se refieren a curas que habían sido ya visitadores de idolatrías anteriormente, tratándose para algunos del segundo pleito que les afectaba. En esta serie se encuentra un nuevo elemento originado en la dinámica puesta en marcha con la denuncia de Avila en 1610: el arma que suponía la acusación de idólatra contra las comunidades. Esto dará lugar a nuevos conflictos, incluso entre los mismos curas, que si bien ya tenían antecedentes por otros motivos, ahora iban a tenerlos también por choques en el asunto de la extirpación.

Así, en 1615, se conoce la visita eclesiástica seguida por un visitador titular de idolatrías, Fernando de Avendaño, contra otro delegado, Plácido Antolínez, encargado de visitar su propia parroquia de Ocros. En el proceso habido se probó que Antolínez había sustraído ilegalmente diversos objetos de plata y oro

El documento del pleito se encuentra en A.A.L., Capítulos, 2.

59) De hecho han sido mencionados todos los que se conocen hasta 1615, excepto Diego Ramírez que era cura en Lima. 
de la communidad y que habia tomado tributos de manera arbitraria ${ }^{60}$.

Continuando en orden cronológico, en 1617 de nuevo Luis de Mora y Aguilar, a quien ya conocemos, se vió involucrado en otro pleito $^{61}$. En esta fecha Mora y Aguilar era doctrinero de Pariamarca, en el repartimiento de Canta, y fue acusado por dos indios del pueblo de San Francisco de Llachac que acudieron a Lima a quejarse de él. Los cargos eran muy variados y se referían esencialmente al uso de mano de obra indígena sin remunerar, a apropiación indebida de productos, a intervención comercial y a faltas de asistencia religiosa. Tras una prolongada estancia en Lima de los dos indios en espera de que se encargase la averiguación del caso a persona competente, el Provisor comisionó al P. Cristóbal de Castilla, cura de la doctrina de Quibi, vecina de la de Mora, para que iniciara la información de los hechos. Para facilitar la libre expresión de los indios en los interrogatorios se decretó la salida del doctrinero acusado de su distrito $y$, tras esto, nada más se sabe del caso. La resolución, sin embargo, debió ser favorable al cura porque dos años más tarde continuaba de titular en la misma doctrina de Pariamarca ${ }^{62}$.

En 1619 es otra vez Alonso Osorio el que se vió envuelto en un problema judicial. En efecto, después de una visita de extirpación realizada en dicho año, los indios del pueblo de Ambar, en Cajatambo, lo acusaron de haber obtenido falsas declaraciones de ellos torturándolos $\mathrm{y}$ de haber hecho vender tierras que les pertenecían. Los indios las reclamaban, a pesar de que un hechicero citado por la defensa afirmaba que se trataba de tierras de huacas $^{63}$. Desgraciadamente, la fuente de información de este caso no aporta nada más sobre el mismo.

Otro Visitador de Idolatrías en la primera campaña fue Francisco Estrada Beltrán, cura de Mangas ${ }^{64}$. Pues bien, Estrada fue

60) Exhibiciones en el pueblo de Ocros. A.A.L., V, 27, 1615. Tomado de P. D u v i o l s, La lutte. . ., 329.

61) V. nota 51.

$62)$ A.A.L., Capítulos, 3.

63) Tomado de P. D u v i o l s, La lutte ..., p. 324, quien da como toda referencia "A.A.L."

64) Cfr. P. J. A r ri a g a, Extirpación..., p. 63. 
acusado de causar agravios a los indios «so color de visitar las idolatrías*, por el pueblo de San Luis de Matará65. Recibida la acusación, al parecer el Provisor arzobispal ordenó que se iniciase la información del caso en la misma ciudad de Lima, por lo que el Protector de Naturales se dirigió al arzobispado solicitando que, dado que no habia testigos de los hechos en Lima y que éstos habian tenido lugar en Matará, donde sí había "copia de ellos", nombrase el Provisor para su averiguación al cura de Lampas o a otro de la provincia, sugiriendo el más cercano para comodidad de los indios.

A partir de esta petición el pleito sufrió una tramitación lentísima y su final, si es que se produjo, no se encuentra en el expediente, tal como nos ha llegado. Dicha lentitud fue debida a sucesivas recusaciones, por ambas partes, de las personas a las que se iba comisionando el caso, así como de un apoderado del fiscal. Sin entrar en mucho detalle, merece darse al menos la relación de los implicados en estas recusaciones para tener una idea del nivel de conflicto de intereses que existía entre los doctrineros del arzobispado.

Los primeros encargados por F. de Vega, el Provisor, "in solidum" para la averiguación del caso fueron Rodrigo Hernández Príncipe, cura de Ocros, y Francisco de Avila, a quienes recusó Estrada, el cura acusado por los indios, por ser personas íntimas de Juan Velázquez $\mathrm{y}$ de su patria $\mathrm{y}$, como consecuencia, enemigos capitales de él. Por su parte, Juan Velázquez, encomendero de los indios en cuestión, era apoderado del fiscal eclesiástico y defensor de los dichos indios (sic); contra él se había presentado una petición para que se ausentase del pueblo de Lampas, por Alonso Pérez de Vivero, presumiblemente defensor de Estrada $^{66}$. Más adelante, en 1621, el fiscal recusó a un nuevo encargado del caso por el Provisor, el Ldo. Juan Sánchez Almaraz, por ser amigo íntimo de Estrada ${ }^{67}$. Este, a lo largo de todo el

65) A.A.L. Capítulos, 4.

66) Alonso Pérez de Vivero, como doctrinero de S. Pedro de Mama, estuvo envuelto en pleitos con sus indios en 1605 y 1607 . A.A.L., Capitulos, 1.

67) Juan Sánchez de Almaraz, como cura de Huacaybamba, estuvo involucrado en otro proceso judicial en 1629. A.A.L., Capítulos, 6 . 
pleito, no dejaba de afirmar que la causa había sido promovida por Velázquez y en este estado de marasmo se detuvo, quizás definitivamente, el asunto.

En el mismo año de 1621, el Maestro Julián de los Ríos, un nuevo visitador de la primera campaña que aquí se comenta ${ }^{68}$, siendo cura de Moyobamba, en Checras, fue acusado por la comunidad del pueblo de Los Reyes de Chinchaycocha, donde había sido doctrinero Alonso Osorio, por considerar que De los Ríos los había infamado al acusarles de idólatras. Los indios sostenían que, desde que fueron visitados en Noviembre de 1612 por el Dr. Diego Ramírez, y absueltos, después de convencerse de sus errores, no habían vuelto a practicar las idolatrías ${ }^{69}$.

La querella fue presentada por Don Carlos Guamanatoc, cacique principal de Piscapachaca de dicho pueblo, y otros indios principales. En ella afirmaban que Julián de los Ríos se había informado que no había errores de idolatría entre ellos y que, los que declaró al acusarlos, los inventó quizás para justificar los meses que permaneció en el pueblo gastando las haciendas de los indios. Como en otros muchos casos, de este pleito tampoco se conoce el final.

El último proceso se refiere a Plácido Antolínez, del que ya se ha hablado anteriormente ${ }^{70}$. En 1623, siendo cura en Los Reyes de Chinchaycocha, fue acusado por Don Lorenzo Puypachagua, alcalde ordinario de San Cristóbal de Pacasmayo, de haberle azotado hasta hacerle sangrar, en la sacristía de la iglesia de San Pedro de Cacas. El motivo del castigo era que Puypachagua había declarado contra Antolínez en otro pleito que los indios le habian puesto con anterioridad y tras el cual, obviamente, el cura había permanecido en la doctrina.

En el desarrollo de la información sobre este nuevo caso, Antolínez, que fue preventivamente encarcelado, negó los hechos que se le imputaban e intentó desprestigiar al indio negándole el "don" y llamándole "Lorencillo". Este, por su parte, probó con testigos su cargo en la comunidad y declaró sobre los excesos

68) Cfr. P.J. A r r i a g a, Extirpación..., p. 101.

69) A.A.L., Capítulos, 4.

70) Cfr. P. J. A r ri a ga, Extirpación ..., p. 9. V. también supra nota 55. El pleito se encuentra en A.A.L., Capítulos, 4. 
cometidos por el cura en la doctrina y, en particular, sobre la muerte de Don Lucas Condor Atoc, por mano del cura "a coces", como consecuencia de las cuales estuvo tres días moribundo. Acerca de este caso, según Puypachagua, nadie se atrevía a declarar en la doctrina.

Pero, a pesar de la gravedad de los hechos, las partes llegaron a un acuerdo ante el comisionado por el Provisor para el caso, el vicario de Vico y Pasco, Francisco Arroyo Naharro ${ }^{71}$, por el que Puypachagua desistía de seguir el pleito, perdonando cualquier injuria "por servicio de Dios Nuestro Señor y porque [Antolínez] le ha dado y pagado 50 pesos de a ocho, los 12 en reales. y los demás que Juan López Mestanssa [?] le ha quedado en pagar por el susodicho, de que le ha dado una cédulan.

\section{V. Conclusión}

Los casos examinados muestran que, prácticamente, todos los visitadores de idolatrías que menciona $\mathrm{A}$ r $r$ i a g a en su obra " $\mathrm{La}$ extirpación de la idolatría. .. ", salvo Diego Ramírez, los jesuitas que los acompañaban, que no eran visłtadores propiamente dichos y otros dos curas, estuvieron envueltos en procesos judiciales de diverso tipo, con el denominador común del "agravio» a los indios, expresión de contenido económico que encierra la utilización de su fuerza de trabajo y la apropiación de sus recur$\operatorname{sos}^{72}$.

Para defender la tesis de este trabajo habría sido de interés estudiar el conjunto de pleitos que se conocen con anterioridad a 1610, de los que los de Avila, Avendaño y Hernández Príncipe forman parte, pero he preferido utilizar sólo éstos últimos, de entre los precedentes, y poner énfasis en los que afectaban al grupo de visitadores de idolatrías en la década de 1610. De cualquier forma, la idea de que estos procesos judiciales, conocidos

$71)$ V. supra nota 54.

72) Estos otros dos son Pedro Ortega y Miguel Rubio. Cfr. P. J. A r r i a g a, Extirpación. .., pp. 63 y 109. Alsono García Cuadrado y Bart. Dueñas, a los que cita en p. 53, pertenecían al obispado de La Paz. 
desde comienzos del XVII, estimularon la actuación de los curas en la extirpación de la religión indígena parece fundamentada.

En los pleitos no era siempre el doctrinero el acusado, aunque siempre tenía que ver con la base económica de las disputas, pero, de hecho, lo fueron todos los que se han examinado menos uno. Tampoco el conflicto tenía que plantearse directamente con los indios. En una ocasión son hacendados y mineros españoles, hay que suponer que afectados por el uso que hacía el cura de la mano de obra indígena, quienes revelan sus actividades. Otra vez es otro cura, probablemente ansioso de ocupar la plaza de titular de la doctrina, el que da lugar al proceso. Otras veces, los pleitos se originan en choques entre los propios visitadores. En cualquier caso, el doctrinero aparece intentando ampliar su cuota de participación en el reparto del excedente económico indígena.

En otro sentido, de la variedad de posibilidades que produce la pugna de intereses confluyentes se derivan, a veces, situaciones confusas provocadas por la manipulación de los casos, consistentes esencialmente en la utilización de los indios en beneficio de cualquiera de los litigantes. Por un lado, se puede convercerlos para presentar capítulos contra el cura: capítulos falsos, exagerados $o$, incluso, ciertos pero buscando aumentar el número de acusadores o testigos. De todas formas, siempre parece existir, detrás de estas inducciones, un fondo de verdad en las acusaciones que se confirma de hecho en los casos más claros de manipulación, como parecen ser los de Avila y Osorio en 1613. Por otra parte, sin embargo, las manipulaciones pueden producirse en beneficio del cura, como es el encubrimiento de sus actividades por la propia comunidad influida por sus caciques.

Todo ello sin detenerse en el aspecto judicial, en general, de los pleitos que merecería un análisis en sí mismo. Del conjunto de los casos parece desprenderse una actitud de las autoridades arzobispales, particularmente del Provisor Felíciano de Vega, pero también del mismo arzobispo Bartolomé Lobo Guerrero, tendente a paliar y a pasar por alto las acusaciones contra los doctrineros, tanto en el plano de los trámites de los procesos como en el de las sentencias: nombrando a comisionados vinculados a alguna de las partes, alargando o deteniendo indefinidamente los procesos, permitiendo composiciones entre los litigantes, ignorando 
acusaciones probadas, imponiendo condenas mínimas cuando éstas tenían lugar, manteniendo a los curas en las mismas doctrinas donde habían tenido los conflictos o, sencillamente, trasladándolos a otras nuevas. Todo ello agravaba la ya de por sí desigual relación entre curas e indios.

En parte esto no es extraño, así como tampoco que Lobo Guerrero eligiera como primeros Jueces de Idolatrías a curas que habían estado implicados en pleitos por perjuicios a intereses indígenas y que no habían salido airosos de ellos. No es extraño si se recuerda que, siendo arzobispo de Santa $F e$, ya se había destacado como defensor de doctrineros que tenían problemas con sus comunidades, aunque en aquel caso se dirimiera también el principio de la jurisdicción eclesiástica. De aquel tiempo databa también el comienzo de su intervención en contra de las órdenes religiosas ${ }^{73}$. Ya en Lima, mientras que en el Tribunal Eclesiástico se conocían los pleitos contra los clérigos doctrineros de la archidiócesis a los que se trataba benévolamente, Lobo Guerrero elaboraba dos informes, en 1612 y 1614 , en contra de los religiosos doctrineros, en los que los testigos que se buscaron acusaban a los frailes de mantener actividades económicas en sus doctrinas y recomendaban su sustitución por clérigos "hijos de la tierra" a los que se consideraba mucho más virtuosos. Por el contrario, en la correspondencia del arzobispo con la Corona sólo se encuentra alguna breve referencia a los numerosos problemas de los doctrineros clérigos que conoció su Tribunal a todo lo largo de su mandato ${ }^{74}$. Para entender esta actitud quizás es conveniente no

73 ) A. de E g a ñ a, op. cit., p. 506.

74) V. Informaciones promovidas por Lobo Guerrero citadas en nota 30 supra. Sobre el uso de esta documentación para el estudio del tratamiento del terna de las doctrinas por Lobo Guerrero, v. P. C a s t a h e d a, "Don Bartolomé Lobo...", op. cit., p. 66 y ss. y A. A c os t a, "Religiosos, doctrinas y excédente económico indígena en Perú a comienzos del siglo XVII", en prensa en la Revista Histórica, Lima.

Contraponer dichas informaciones y sus otros muchos ataques a los religiosos con la breve referencia a los problemas de los clérigos doctrineros en la carta del arzobispo a S.M. de 20 de Abril de 1611, en: La Iglesia de España en el Perú (Colección de documentos dirigida por Mr. Emilio Lissón Chaves). Sevilla 1946, Vol. IV, no. 22, p. 626.

Es interesante tener en cuenta la referencia que da P. D u vi o l s en: La Lutte.... p. 329, acerca de la existencia de una "Información Secreta" 
olvidar la disputa que por estos años se comenzaba a agravar por causa de los diezmos, que enfrentaba a los sectores regular y secular de la Iglesia ${ }^{75}$.

Una vez iniciada la campaña de 1610 , las posibilidades económicas de los doctrineros, en general, no hicieron más que aumentar. Por un lado, los que fueron nombrados visitadores de idolatrías mantuvieron sus puestos como titulares de doctrinas o, incluso, ascendieron en los primeros momentos. Avila, por ejemplo, fue ascendido antes de de ser nombrado Juez Visitador. Pero, además, aprovechaban las posibilidades que les brindaban las mismas visitas para apropiarse directamente de bienes de los indios, como en el caso de Antolínez que se ha examinado; para organizar repartos masivos de rosarios en los que algunos ya tenian experiencia; o para recoger limosnas en colectas extraordinarias, aprovechando quizás la mala conciencia de los indios después de sus confesiones de idolatrías, en las que, a veces, se obtenían en un solo pueblo y día hasta 340 pesos $^{76}$.

Por su lado, el resto de los doctrineros no dejaba de recibir también un cierto beneficio, como se puede considerar el amplio movimiento de fundación de cofradías con advocaciones marianas que se llevó a cabo con ocasión de las visitas ${ }^{77}$. Aunque no se puede pecar de simplista estableciendo una relación directa de causa efecto entre cofradía y aumento de la cantidad de excedente apropiado por el doctrinero, porque el funcionamiento de la cofradía era bastante complejo, existen ejemplos que prueban que dicha relación se daba.

En términos generales, los doctrineros conseguían una salida ventajosa, tanto en el terreno de los beneficios materiales directos

llevada a cabo tras la muerte de Bartolomé Lobo Guerrero en 1622, por la Sede Vacante de Lima, sobre los más conocidos visitadores de la idolatría, de la que, desgraciadamente, no se conocen los resultados, si es que se concluyó.

75) V.P. C a s t añ e d a y J. March e na, "Lasórdenesreligiosas en América: Propiedades, diezmos, exenciones y privilegios». Anuario de Estudios Americanos. Vol. XXXV. Sevilla 1978, pp. 125-158.

76) R. Hernández Príncipe enviaba dinero, seguramente de los indios, desde los pueblos que visitaba a Arriaga, quien le compraba y remitía rosarios que aquél repartía entre los indios. v. P.J. A r $r$ i a g a, Extirpación ...., p. 54 . Acerca de colectas de limosnas, v. ibid., pp. 61 y 67 .

77) Sobre fundación de cofradías, v. ibíd., pp. 55, 56, 60, 62 y 67. 
como en el del prestigio y ascenso social. Aparte de la experiencia de Avila y Avendaño, el Rey enseguida recomendó gratificar a los curas que se destacasen en la extirpación de las prácticas religiosas indígenas, considerandolos prioritariamente a la hora de proceder a ascensos en la organización eclesiástica ${ }^{78}$.

Dado el estado por el que pasaban los doctrineros a comienzos del siglo XVII, la iniciativa de Avila de denunciar aparatosamente las idolatrías de sus indios significaba una especie de salida hacia adelante en su embarazosa situación. Con ella se puso en marcha una reacción en la que cabe ver una maniobra de distracción con la que conseguían hacer recaer muchas de las tensiones existentes entre diferentes sectores de la sociedad colonial, en medio de las cuales se encontraban los propios curas, sobre el origen de todas ellas: la población indígena. Y ello valiéndose de un recurso sobre el que existían garantías sobradas de sensibilidad por parte de las autoridades coloniales: la pervivencia de la religión indígena ${ }^{79}$.

Los doctrineros, con Avila a la cabeza, utilizaron inteligentemente resortes sociales muy eficaces en la presentación de la campaña, como la capacidad de asombro de la sociedad blanca limeña, una gran dosis de teatro y su gran conocimiento del tema, aparte de la inestimable colaboración que les brindaba el interés por la cuestión de Lobo Guerrero. La campaña que se inició en 1610 tuvo, por todas estas características, una naturaleza diferente a la del resto de movimientos antiidolátricos, que fueron promovidos mayormente por el celo evangelizador o de colonización en el plano religioso. Ahora se trataría de una reacción de una parte del sector doctrinero, que había sido durante mucho tiempo transigente, en mayor o menor grado, con las prácticas indíge-

78) S. M. al virrey Príncipe de Esquilache. Madrid, 28 de Marzo de 1620. Biblioteca Nacional de Madrid, MS. 19282, fol. 155.

79) P. D u vi ols sólo incluye un último capítulo en su obra: La lutte ... dedicado al aspecto económico de la extirpación que denomina «Circonstances économiques de l'extirpation», con un apartado titulado «Extirpation et corruption"). En éste comenta la corrupción de los doctrineros con cuatro casos de capitulos contra algunos de ellos, posteriores a 1620. En ningún caso relaciona este aspecto económico con la aparición de las denuncias de las idolatrías, salvo en la sospecha que levantó por la referencia del pleito de Avila hecha por J. T. Polo, v. op. cit., pp. 297-336. 
nas y que, por determinadas circunstancias, iba a dejar de serlo para utilizar con gran fuerza el tema de la religión indígena en su beneficio.

En un mundo donde los curas pugnaban por tener acceso a una parte cada vez mayor del excedente económico de la población india, que, por su parte, continuaba descendiendo numéricamente, era inevitable la aparición de choques primeramente con los indios mismos, pero también con corregidores, encomenderos y con otros curas, los cuales perseguían objetivos similares. De esta manera se entiende que el origen y la causa principal del movimiento contra las idolatrías de comienzos del siglo XVII estaba en el interior de las doctrinas y era el resultado de cambios habidos en las estructuras de la sociedad colonial.

Hay que hacer notar que la denuncia de Avila tiene la particularidad de que es la primera vez que un movimiento contra la religión indígena nace dentro de la doctrina de indios y llega hasta la puesta en evidencia del hecho ante la autoridad episcopal. Hasta entonces, las iniciativas de extirpación habían partido de fuera del ámbito de la doctrina, pero Avila fue el primer doctrinero que dio ese paso. Con ello entró en una gran contradicción. Como más tarde se escribiría, una de las razones fundamentales que la Iglesia encontraba para explicar la permanencia de las prácticas indigenas era la falta de suficiente evangelización, falta que era responsabilidad de los encargados de ella, es decir, de los doctrineros ${ }^{80}$. Al organizar la denuncia de la idolatría, Avila quedaba en evidencia en ese sentido, mostrando implícitamente que no había sido un buen doctrinero, de acuerdo con los criterios imperantes en la propia Iglesia. No obstante ello, a Avila y a todos los demás se les reconocería la capacidad de extirpar la idolatría por métodos más expeditivos que el de la enseñanza de la doctrina católica, en sus propias doctrinas y en las de los demás curas.

Desde el punto de vista de la organización eclesiástica, en el lado extirpador hay que matizar y distinguir varios componentes que posiblemente respondieran a diferentes móviles:

80) P. J. A r r i a g a, Extirpación...,pp. 38-9 y Pedro de V i l l a g ó m e z, Carta Pastoral de exortacion a instruccion contra las idolatrías del arzobispado de Lima. Lima 1649, fol. 16. 
1) Los doctrineros, de quienes ya se ha comentado las circunstancias que los rodeaban.

2) Los jesuitas, a los que avisó Avila en 1609 y que, ayudados por la confianza que les prestaba Lobo Guerrero, pasaron a ser asistentes imprescindibles para los visitadores ${ }^{81}$. Hacía tiempo que se habían preocupado por el tema $y$, precisamente, en el mismo Huarochirí, aunque después parece que perdieron interés o creyeron que habían acabado con las prácticas religiosas de los indios $^{82}$. Es curioso observar que en la explicación que da A r $\mathrm{r}$ i a $g$ a, jesuita él mismo, al asombro de parte de la sociedad colonizadora ante la denuncia de la existencia de las idolatrías, no hace mención a la antigua presencia jesuita en Huarochirí y a su atención al tema, sino sólo a la de Toribio Mogrovejo. A r r i a g a se hace eco de la pregunta de un sector de la sociedad en el sentido de cómo era posible que perduraran las prácticas indias si Mogrovejo, con toda su capacidad y saber, había visitado personalmente no hacía tanto su arzobispado. La respuesta de A r $r$ i a g a era que quizás Mogrovejo estuviera logrando más favores desde el cielo que lo que él pudo conseguir con su presencia en la tierra.

3) Bartolomé Lobo Guerrero. Aparte de sus condiciones personales, algunas ya comentadas, es necesario insistir en el marco de la disputa entre el clero regular y el secular por motivos muy concretos que se relacionan con la evolución de las estructuras económicas del virreinato.

Desde otro punto de vista completamiente diferente, aunque también con interés en cuanto a las relaciones sociales, no se puede dejar de mencionar que, en el ejercicio de la tarea de los doctrineros, cobra especial importancia el grupo de personas que se constituye a su alrededor, sirviéndole de apoyo. Grupo compuesto por elementos indígenas y no indígenas que, en muchas ocasiones, contribuirán con el cura a erosionar el poder del cacique en la comunidad. Al acudir directamente a ésta recabando de ella

81) R. Vargas $U$ gar t e, Historia de la Iglesia en el Perú. Burgos $1956-60$, vol. II. pp. 309 y ss.

82) Monumenta Peruana, Roma 1954..., vol. I, doc. 85, pp. 420-5, tomado de P. Duviols, La lutte..., p. 111; y vol. II, doc. 26, pp. 230-2, tomado de: Dioses y hombres. ... pp. 240-2. 
distintos tipos de servicios, el cura y este grupo que lo rodea están transformando esencialmente el papel del cacique frente a los indios basado en las relaciones de parentesco ${ }^{83}$ :

Ni que decir tiene que, a pesar de los términos en que está concebido este trabajo, no pretendo reducir la explicación de las campañas de idolatrías del siglo XVII a motivos exclusivamente económicos. La complejidad de las relaciones sociales y de las estructuras mentales, tanto del mundo colonizado como del colonizador, completan, junto a los problemas económicos, un cuadro suficientemente complicado como para reducir un fenómeno como las campañas extirpadoras de la idolatría a una sola explicación. Pero considero que el planteamiento expuesto es esencial para entender correctamente la historia de este movimiento a cominezos del XVII. Si se puede prescindir de algunos aspectos del mismo y entender su esencia, al menos parcialmente, creo que no se puede prescindir de la perspectiva de la dominación colonial, que determina conflictos como los mostrados, y en la que juega un papel fundamental la apropiación del excedente económico indígena.

Nada se ha dicho aquí, por lo demás, acerca de las consecuencias de las campanas de idolatrías, en sí mismas, sobre la organización social indígena, aspecto muy importante que merece un tratamiento específico ${ }^{84}$. En cuanto al desarrollo posterior de la extirpación, ya avanzado el siglo XVII, quizás pueda ser sometido a explicaciones diferentes a las ofrecidas aquí. Es un terreno abierto a la investigación. En principio, algunas de las ideas que circulaban en la época del arzobispo Villagómez, que expresaban que los curas transigían con las idolatrías y no las denunciaban por temor a verse capitulados por los indios ${ }^{85}$, no parecen sostenerse si se observan a la luz de los hechos que hemos estudiado.

83) Cfr. el análisis de K. S p a $\mathrm{l}$ d i n g, «Los escaladores sociales . . .), op. cit. pp. $61-87$.

84) Sobre este tema v. el sugerente párrafo de K. S p a l d ing en «La red. . .l, op. cit., pp. 121-2.

85) P. D u vi ols, La lutte ..., p. 322. 